\title{
Computed Tomographic Evaluation of Calvarial Thickness
}

\author{
Ankur Shah ${ }^{1}$, Anup Pradhan ${ }^{2}$ \\ ${ }^{1}$ Associate Professor, Department of Radiology, KIST Medical College, ${ }^{2}$ Assistant Professor, Department of Radiology, KIST Medical College.
}

\section{Abstract}

Background: Majority of the cranial bones are characterized as flat bones and can be recognized because of their layered bony structure whereas the cancellous bone layer, is known as diploe, and it lies between two layers of dense cortex. The advent of Computed tomography has revolutionized the technology of imaging and diagnosis of the calvarium during the last few years. The present study was done to evaluate the calvarial thickness by CT. Subjects and Methods: This cross sectional observational study, was carried out on a total of 178 subjects undergoing CT Scan of Head in the department of Radiology. The frontal bone was divided into lower, middle and upper third. Similarly, the parietal and occipital bones were also divided into three parts namely anterior, middle and posterior third. All the data was arranged in a tabulated form and analyzed using SPSS software. Student $t$ test was used for comparison. Probability value of less than 0.05 was considered as significant. Results: The mean age of the subjects was 38.98 years (Range 17 to 76 years). The posterior 3 rd parietal thickness amongst males was $4.60+0.91$ and females was $5.54+1.63$. Difference of calvarial thickness between male and female at this point was statistically significant. The anterior 3 rd parietal thickness on right side was $4.89+0.79$ and on left side was $4.45+0.93$. There was a significant difference between the two. Conclusion: The present study shows that the thickness of anterior third of the parietal bone on the right side was more than on the left side amongst both males and females. It also shows that the posterior 3rd parietal thickness among female was more than males.

Keywords: Calvarial, parietal, occipital.

Corresponding Author: Dr Ankur Shah, Associate Professor, Department of Radiology, KIST medical College, Nepal.

Received: January 2019

Accepted: February 2019

\section{Introduction}

The chief function of skull is protection of the brain. It is made up of 22 bones, 8 of which comprise the neurocranium and are joined by synarthrodial joints known as sutures. Majority of the cranial bones are characterized as flat bones and can be recognized because of their layered bony structure where the cancellous bone layer, diploë lies between two layers of dense cortex. Past studies have used cadavers and primates to estimate the mechanical assets of the skull. ${ }^{[1,2]}$ A study by McElhaney et al evaluated spatial, materialistic and structural properties of skull from the samples taken from the cadavers. ${ }^{[1]}$ The flexural stiffness and strength of skull was demonstrated by Hubbard et al by a layered beam testing technique. ${ }^{[2,3]}$ The studies came to the conclusion that flexural properties of skull are highly dependent on the thickness of skull. The cortical thickness of outer table of the skull has been estimated and reported at different locations across the skull by Peterson et al. ${ }^{[4]}$ The advent of Computed tomography has revolutionized the technology of imaging and diagnosis of the calvarium during the last few years. Computerized tomography scan has been found to be useful for the measurement of the calvarial thickness amongst human beings. This is found to be very useful in identifying the racial and the gender discrepancies in calvarial thickness amongst a population. The information obtained about the calvarial thickness studies amongst human subjects can be useful for researchers, anthropologists, surgeons and producers of surgical screws. ${ }^{[5-8]}$ It can also be helpful in reconstructive plastic surgeries as skull is one of the frequently used location of bone graft harvesting. Past studies from Chinese, and Japanese population have tried to estimate the cranial thickness with contradictory results about the association between cranial thickness and age, sex and body build. ${ }^{[6-8]}$ The present study was done to evaluate the calvarial thickness by CT.

\section{Subjects and Methods}

The present cross sectional observational study, was carried out with a CT scan of the head by 16 slice Toshiba CT Scan machine. The study enrolled a total of 178 subjects out of which 90 were male and 88 were females. The subjects were informed about the study and a written consent was obtained from them in their vernacular language. Ethical committee clearance was obtained from the institutional ethical board. The subjects with skull vault fractures or any intracranial lesion were not included in the study. The skull bone thickness was measured on console. The frontal, parietal and occipital were further divided for into 3 parts each for the purpose of consistency and equality of measurement and were measured using CT scan. The Frontal, parietal and occipital bones were measured on both 
right and left side and compared with each other. The frontal bone was divided into lower third at the sinus level, middle third at tuberosity level and above tuberosity was considered as upper third. Similarly, the parietal and occipital bones were also divided into three parts namely anterior, middle and posterior thirds. At 95\% confidence level, assuming the standard deviation of $0.34 \mathrm{~mm}$ of thickness of cranial vault and maximum tolerable error of $0.5 \mathrm{~mm}$ from mean, the minimum sample size is calculated as 178 . The study used retrospective data from August 2017 to July 2018. The sample of 178 cases was selected using simple random sampling from the total cases recorded in department of Radiodiagnosis and Imaging, Kist Medical College. The difference in the values amongst the males and females were established. All the data was arranged in a tabulated form and analysed using SPSS software. Student $t$ test was used for comparison. Probability value of less than 0.05 was considered as significant.

\section{Results}

The study enrolled 178 subjects out of which 90 were male and 88 were females. The mean age of the subjects was 38.98 years (Range 17 to 76 years). [Table 1] shows the Comparison of thickness of calvarial bone at different points in male and female population. The Upper 3rd frontal thickness amongst males was $6.15+1.02$ and females was $6.29+.0 .92$. The middle 3rd frontal thickness amongst males was $6.36+1.41$ and females was $6.34+1.04$. The lower 3rd frontal thickness amongst males was $6.41+1.12$ and females was $6.98+1.41$. The anterior 3 rd parietal thickness amongst males was $4.56+0.76$ and females was $4.70+0.2$. The middle 3 rd parietal thickness amongst males was $4.34+0.72$ and females was $4.58+0.68$. There was no significant difference between male and female in above mentioned data. The posterior 3rd parietal thickness amongst males was $4.60+0.91$ and females was $5.54+1.63$. There was significant difference in thickness between male and female in posterior 3rd parietal bone. The anterior 3rd occipital thickness amongst males was $8.11+1.01$ and females was $7.98+1.18$. The middle 3 rd occipital thickness amongst males was $8.30+1.33$ and females was $8.29+1.59$. The posterior 3rd occipital thickness amongst males was $9.98+2.61$ and females was $9.69+1.84$. There was no significant difference in occipital bone thickness between male and female in above mentioned data.

[Table 2] shows the comparison between the frontal, parietal and occipital bone thickness on right and left side. The upper 3rd frontal thickness on right side was $6.15+1.02$ and left side was $6.11+.0 .92$. The middle 3 rd frontal thickness on right side was $6.36+1.41$ and on left side was $6.24+1.02$. The lower 3 rd frontal thickness on right side was $6.51+1.12$ and females was $6.68+1.32$. There was no significant difference in frontal bone on both sides. The anterior 3rd parietal thickness on right side was $4.89+0.79$ and on left side was $4.45+0.93$. There was a significant difference between the two. The middle 3rd parietal thickness on right side was $4.45+0.70$ and on the left side was $4.46+0.76$. The posterior 3 rd. parietal thickness on right side was $5.12+1.21$ and on left side was $5.09+1.14$. The anterior 3rd occipital thickness on right side was 8.15 +1.01 and on left side was $8.34+1.16$. The middle 3rd occipital thickness on right side was $8.30+1.33$ and on left side was $8.29+1.59$ The posterior 3rd occipital thickness on right was $9.78+1.61$ and on left side was $9.69+1.84$. There was no significant difference between the both sides in above mentioned data.

Table 1: Comparison of thickness of calvarial bone at different points in male and female population.

\begin{tabular}{|l|l|l|l|}
\hline Thickness & Male & Female & P value \\
\hline $\begin{array}{l}\text { Upper 3rd frontal } \\
\text { (mm) }\end{array}$ & $6.15+1.02$ & $6.29+.0 .92$ & $<0.05$ \\
\hline $\begin{array}{l}\text { Middle 3rd } \\
\text { frontal (mm) }\end{array}$ & $6.36+1.41$ & $6.34+1.04$ & $<0.05$ \\
\hline $\begin{array}{l}\text { Lower 3rd frontal } \\
\text { (mm) }\end{array}$ & $6.41+1.12$ & $6.58+1.41$ & $<0.05$ \\
\hline $\begin{array}{l}\text { Anterior 3rd } \\
\text { parietal (mm) }\end{array}$ & $4.56+0.76$ & $4.64+0.62$ & $<0.05$ \\
\hline $\begin{array}{l}\text { Middle 3rd } \\
\text { parietal (mm) }\end{array}$ & $4.34+0.72$ & $4.58+0.68$ & $<0.05$ \\
\hline $\begin{array}{l}\text { Posterior 3rd } \\
\text { parietal (mm) }\end{array}$ & $4.60+0.91$ & $5.54+1.63$ & $>0.05$ \\
\hline $\begin{array}{l}\text { Anterior 3rd } \\
\text { occipital (mm) }\end{array}$ & $8.11+1.01$ & $7.98+1.18$ & $>0.05$ \\
\hline $\begin{array}{l}\text { Middle 3rd } \\
\text { occipital (mm) }\end{array}$ & $8.30+1.33$ & $8.29+1.59$ & $>0.05$ \\
\hline $\begin{array}{l}\text { Posterior 3rd } \\
\text { occipital (mm) }\end{array}$ & $9.98+2.61$ & $9.69+1.84$ & $>0.05$ \\
\hline
\end{tabular}

Table 2: Comparison of calvarial bones at different points on both right and left sides

\begin{tabular}{|l|l|l|l|}
\hline Thickness & Right side & Left side & P value \\
\hline $\begin{array}{l}\text { Upper 3rd frontal } \\
(\mathrm{mm})\end{array}$ & $6.15+1.02$ & $6.11+.0 .92$ & $<0.05$ \\
\hline $\begin{array}{l}\text { Middle 3rd } \\
\text { frontal (mm) }\end{array}$ & $6.36+1.41$ & $6.24+1.02$ & $<0.05$ \\
\hline $\begin{array}{l}\text { Lower 3rd frontal } \\
(\mathrm{mm})\end{array}$ & $6.51+1.12$ & $6.68+1.32$ & $<0.05$ \\
\hline $\begin{array}{l}\text { Anterior 3rd } \\
\text { parietal (mm) }\end{array}$ & $4.89+0.79$ & $4.45+0.93$ & $>0.05$ \\
\hline $\begin{array}{l}\text { Middle 3rd } \\
\text { parietal (mm) }\end{array}$ & $4.45+0.70$ & $4.46+0.76$ & $<0.05$ \\
\hline $\begin{array}{l}\text { Posterior 3rd } \\
\text { parietal (mm) }\end{array}$ & $5.12+1.21$ & $5.09+1.14$ & $<0.05$ \\
\hline $\begin{array}{l}\text { Anterior 3rd } \\
\text { occipital (mm) }\end{array}$ & $8.15+1.01$ & $8.34+1.16$ & $<0.05$ \\
\hline $\begin{array}{l}\text { Middle 3rd } \\
\text { occipital (mm) }\end{array}$ & $8.30+1.33$ & $8.29+1.59$ & $<0.05$ \\
\hline $\begin{array}{l}\text { Posterior 3rd } \\
\text { occipital (mm) }\end{array}$ & $9.78+1.61$ & $9.69+1.84$ & $<0.05$ \\
\hline
\end{tabular}

\section{Discussion}

Skull bone comprises of the inner, outer table and the diploe of cancellous bone in between ${ }^{[5]}$ Computed tomography has transformed the imaging studies of living human beings as the images in cross sectional form can be visualized. In today's era, Computed Tomography has become a useful means for studying the thickness of calvarial bone amongst living subjects. One of prime advantages of using Computed Tomography scan for studying calvarial thickness amongst living subjects is assessment of any 
gender and racial disparity. Additionally, effect of nutrition, occupation and geography on development of calvarial bone and thickness can be studied. ${ }^{[6]}$ A variety of studies have performed different radiological tests for assessing the thickness of cranial bone like ultrasound, CT and MRI. The human skull thickness is variable and in general women tend to have thicker skulls compared to male counterparts. ${ }^{[8]}$ Different authors have seen a mild increase in cranial thickness with advancing age and have attributed it in the frontal bone due to hyperostosis frontalis interna. ${ }^{[9-11]}$ Whereas, other authors concluded an age-related increase in thickness, as a result of discrepancies in the radiologic examination. ${ }^{[12,13]}$ It is thought that hyperostosis frontalis interna is as a result of prolonged oestrogen production amongst females. ${ }^{[14]} \mathrm{A}$ study by Ross et al found a $10 \%$ incidence of hyperostosis frontalis amongst females. ${ }^{[7]}$ As per Ishida and Lynnerup there was no significant association between age and thickness of diploe. ${ }^{[15,16]}$ In our study, The posterior 3rd parietal thickness amongst males was 4.60 +0.91 and females was $5.54+1.63$ and the difference in thickness between the two was statistically significant. The anterior 3rd parietal thickness on right side was $4.89+0.79$ and on left side was $4.45+0.93$ which was statistically significant, This may be in regard to the racial differences between the present study and study by Ross. ${ }^{[14]}$ Various investigators performed computed tomographic study of calvarial bones at different perspectives. As per Gerhard et al on mapping the thickness of the Occipital bone on computed tomographic data and concluded that information regarding the thickness of cranial bones are of great medical interest and also for pre-operative surgical planning, as well as for investigations of fossil hominid material. ${ }^{[16]}$ Ross MD et al studied skull thickness amongst Black and White races and found that White females have the thickest and White males the thinnest skulls. The calvaria of females were statistically thicker than those of men amongst both ethnic groups. ${ }^{[14]}$ In contrast to the Ross et al finding, Hatipoglu $\mathrm{HG}$ et al found sexual dimorphism in all the craniometric data. ${ }^{[17]}$

\section{Conclusion}

The present study shows that the anterior 3rd parietal bone thickness on the right side was significantly more than on the left side amongst both males and females. Whereas, the female calvarium thickness was more at the posterior 3rd of the parietal bone. However more studies involving a larger population is recommended to validate these findings.

\section{References}

1. MCELHANEY, J. H., FOGLE, J. L., MELVIN, J. W., HAYNES, R. R., ROBERTS, V. L. and ALEM, N. M. (1970). "Mechanical properties of cranial bone." Journal of Biomechanics 3(5): 495-511.

2. HUBBARD, R. P. (1971). "Flexure of layered cranial bone." Journal of Biomechanics 4(4): 251-263.

3. HUBBARD, R. P., MELVIN, J. W. and BARODAWALA, I. T. (1971). "Flexure of cranial sutures." Journal of Biomechanics 4(6): 491-496.

4. PETERSON, J. and DECHOW, P. C. (2002). "Material properties of the inner and outer cortical tables of the human parietal bone." The Anatomical Record 268(1): 7-15.

5. Gregory BA, Snow RD, Brogdon BG, Williams JP. Value of bone window images in routine brain CT: Examinations beyond trauma. Appl Radiol. 1997;26.

6. Baral P, Koirala S, Gupta MK. Calvarial Thicknes of Nepalese skulls-Computerised Tomographic (CT) study. Anat Physiol. 2014,4:140.

7. Li H, Ruan S, Peng X, Xie Z, Wang H, Liu W. The thickness measurement of alive human skull based on CT image. Sheng wu yi xue gong cheng xue za zhi. J Biomed Eng. Shengwu yixue gongchengxue zazhi. 2007;24(5):964-8.

8. Li H, Ruan J, Hao WZ, Wengling L. Investigation of the critical geometric characteristics of living human skulls utilising medical image analysis techniques. Inter $\mathrm{J}$ Vehicle Safety. 2007;2:345-67.

9. Angel L. Skull vault thickness variation. American J Physical Anthropol. 1971;35:272.

10. Schmitt HP, Saternus KS. Beiträge zur forensischen Osteologie. III. Zur Frage der Bestimmung des Individualalters an Hand der Dicke der Schädelkalotte. Zeitschrift für Rechtsmedizin. 1973;72(1):40-9.

11. Ross AH, Jantz RL, Mc Cormick WF. Cranial thickness in American females and males. J Forensic Sci. 1998;43(2):267-72.

12. Israel H. Age Factor and the Pattern of Change in Craniofacial Structures. Ame J Phys Anthropol. 1973;39:111-28.

13. Tallgren A. Neurocranial morphology and ageing-a longitudinal roentgen cephalometric study of adult Finnish women. Ame J Phys Anthropol. 1974;41(2):285-93.

14. Ross MD, Lee KA, Castle WM. Skull thickness of Black and White races. S Afr Med J. 1976;50(16):635-8.

15. Ishida H, Dodo Y. Cranial thickness of modern and Neolithic populations in Japan. Human Biology 1990;62:389-401.

16. Lynnerup N. Cranial thickness in relation to age, sex and general body build in a Danish forensic sample. Forensic Science International. 2001;117:45-51.

17. Weber GW, Kim J, Neumaier A, Magori CC, Saanane CB, Recheis W, et al. Thickness Mapping of the Occipital Bone on CTdata-a New Approach Applied on $\mathrm{OH}$ 9. Acta Anthropologica Sinica 2000;19:52-61.

18. Hatipoglu HG, Ozcan HN, Hatipoglu US, Yuksel E. Age, sex and body mass index in relation to calvarial diploe thickness and craniometric data MRI. Forensic Sci Int. 2008;182(13):46-51.

Copyright: (C) the author(s), 2019. It is an open-access article distributed under the terms of the Creative Commons Attribution License (CC BY 4.0), which permits authors to retain ownership of the copyright for their content, and allow anyone to download, reuse, reprint, modify, distribute and/or copy the content as long as the original authors and source are cited.

How to cite this article: Shah A, Pradhan A. Computed Tomographic Evaluation of Calvarial Thickness. Asian J. Med. Res. 2019;8(1):RD01RD03.

DOI: dx.doi.org/10.21276/ajmr.2019.8.1.RD1

Source of Support: Nil, Conflict of Interest: None declared. 